\title{
ACTIVE CLASSROOMS: GREAT FOR ACADEMIC PERFORMANCE, BUT CAN THEY IMPROVE STUDENT HEALTH? A CRITICAL LITERATURE REVIEW
}

\author{
Mike Swoboda, Grand Canyon University
}

\begin{abstract}
This critical literature review explores the concept of the active classroom to identify past program designs and offer future direction for active classroom programming intended to promote student health and well-being. Active classrooms have long been shown to improve academic performance, but little research has been conducted on the potential health benefits to students and the proposed design of such a program. This review bridges the gap between past methodologies and future programming and offers suggestions for fundamental pedagogical changes to enhance student engagement, activity, and overall health and well-being.
\end{abstract}

Keywords: Active classroom, pedagogy, physical activity, nutrition, physical education

Promoting an active classroom can fundamentally change the pedagogy of instructors and encourage students to engage in the promotion of self-learning. Active learning and the active classroom have historically been defined as, "... instructional activities involving students in doing things and thinking about what they are doing" (Bonwell \& Eison, 1991). This definition can be narrowed to promoting physical activity to supplement or supplant the traditional lecture-based classroom. Educators must also allow more student freedom to explore the classroom space along with potentially pacing the class at a speed that may differ from the projected lesson plan.

The academic benefits of an active classroom appear to unilaterally benefit students in their retention and understanding of the underlying material. While the potential drawback of relinquishing control of the classroom to student learning may present challenges, it also appears to promote student learning and engagement by having students learn by doing instead of listening to a lecture (Phillipson, Riel, \& Leger, 2018). This shift in teaching methodology may also promote student independence in both thought and accountability by not tying their learning strictly to the presentation of information by the instructor (Edwards, 2015). Although active classrooms are traditionally seen in ground programs, their benefit may extend to distance and hybrid learning environments. In one study, undergraduate students in a hybrid course improved critical thinking and problem-solving skills when engaged in the active classroom format (Singh, 2017). Although active classrooms can benefit learners of all ages, adoption at younger ages has shown the greatest response on future performance. Children participating in an active classroom at a young age are more likely to have better academic success and classroom engagement in the future over their less-active classmates (Gonzalez-Sicilia, Briere, \& Pagani, 2019). By improving critical thinking and problem-solving skills, students will be more likely to have long term retention of the material, as well as form a better sense of practical application instead of memorization.

While the academic benefits of an active classroom are clearly established, little has been done to evaluate the efficacy of active classrooms on student health. It is clear students are not receiving enough education on healthy behaviors from a young age - both from schools and professionals - 
which may lead to the development of future unhealthy behaviors and obesity related illnesses (Chilimoniuk et al., 2018). Harris (2014) noted that students in physical education teaching programs were found to have low levels of health and fitness knowledge, which suggests further training may be necessary to successfully implement the required curricula for a healthy active classroom to succeed. Still, research on primary school students found that although math scores improved, physical activity in the classroom had no effect on Body Mass Index (BMI) or physical fitness levels after nine months of in-class activity (Have et al., 2018).

The US Department of Health and Human Services recommends children and adolescents participate in at least 60 minutes of moderate-tovigorous physical activity each day (2018). However, recent estimates found that $81 \%$ of all adolescents are not reaching sufficient levels of daily physical activity (McMichan, Gibson, \& Rowe, 2018). Carlson et al. (2015) suggest classroom-based physical activity must be implemented for students to consistently reach even 30 minutes of daily physical activity.

This critical literature review will evaluate previous methodologies of establishing an active classroom for physical health, as well as offer suggestions for future pedagogical study to implement active classrooms applicable to all age groups and learning styles.

\section{PREVIOUS ACTIVE CLASSROOM METHODOLOGY}

\section{Policy Changes}

Changes to school policies alone does not appear to be enough to maintain long term behavioral changes for student health. Further, school systems implementing policy changes without providing the time, space, and training to implement active classroom activities often results in teachers ignoring the policy and physical activity altogether (Allison et al., 2018). A meta-analysis from Howerton et al. (2007) found only a moderate increase in consumption of fruits and vegetables when school policy was changed to promote greater consumption, but without a concurrent curriculum to reinforce healthy eating. While policy change may be necessary, it is more important to introduce active healthy habits and behaviors in the classroom curriculum to further cement long term behavioral change. Schools should promote the implementation of health-centered active classrooms from an early age and maintain a continuous program throughout primary and secondary schooling. Most acute behaviors can be easily changed, but long-term change is dependent on consistency and reinforcement of healthy habits to ensure continued success (Nilsen, Haverkos, Nebeling, \& Taylor, 2010). Further, the active classroom would contribute to student self-guided change, which Bishop (2018) indicated is essential to long term success with maintaining healthy habits and an overall healthy lifestyle.

\section{Modalities}

Various types of equipment, room setup, and interactive lessons can all be used as the hardware for implementing an active classroom. The use of standing desks without subsequent physical activity in the classroom did not produce increases to physical activity outside the classroom (Silva et al., 2018). However, Silva et al. indicated students spent more time standing and less time sitting while at home after using standing desks in school. Bicycle desk use by secondary education students saw significant improvements in physical activity, caloric use, and heart rate, although no further academic benefits were noted (Fedewa, Cornelius, \& Ahn, 2017). From a health standpoint, low intensity cycling would be an ideal classroom activity, but this must also be balanced with maintaining or improving academic performance.

Active classroom equipment such as trampolines, gym mats, balance beams, and overhead ladders have been used concurrently with developing early language skills. McCradySpitzer, Manohar, Koepp, and Levine (2015) found that students using active classroom equipment had increases in weekly active time outside of school by over 60 minutes compared to peers who did not use active classroom equipment.

\section{Faculty and Curriculum}

Full faculty support is needed for implementation of active classrooms to produce positive change in student health and fitness, as teachers who did not value physical activity in an active classroom saw students become less active (Abi Nader, Hilberg, Schuna, John, \& Gunter, 2018). Promoting active classrooms to educators with little or no physical education experience has exposed several barriers to implementation of an 
active classroom. Linker and Woods (2018) found that educators had a strongly negative perception about incorporating physical activity in STEM classes until provided training on structured exercise and physical activity in the classroom. Similarly, Dinkel, Lee, and Schaffer (2016) indicated barriers to implementation, including lack of personal knowledge, left many teachers only sporadically promoting an active classroom.

Wolfe (2018) suggested in addition to a physically active classroom, the curriculum must present information on healthy eating and physical activity for students to see health benefits from the classroom. Previous research suggests as little as 45-90 minute weekly active education sessions with an emphasis on physical activity and healthy eating was enough to elicit long term positive change on 3rd-6th graders to eat more fruits and vegetables and maintain regular daily physical activity (Wolfe, Scott-Pierce, \& Dollahite, 2018). When students participated in daily five minute structured physical activity prior to lecture, their academic engagement increased, but no significant changes were found for overall physical activity or fitness after 12 weeks of daily physical activity (Podnar, Novak, \& Radman, 2018).

\section{FUTURE RECOMMENDATIONS}

Following a review of the literature, there are several recommendations that can easily enhance activity in the classroom, even without changing the core setup of the classroom space. Behrens et al. (2017) found frequency and intensity of classroom physical activity was highest in younger age groups but decreased significantly during secondary school years. The authors suggested that teachers were more likely to presume students would obtain physical activity from after school programs, and were less likely to devote academic time to physical activity. As part of faculty training and development and implementation of a physically active classroom, all teachers must have a unilateral understanding and support of the program to make success feasible. Martin and Murtagh (2015) noted student acceptance and enjoyment is a necessity of any active classroom design. If students ultimately do not buy in to the concept of an active classroom, forcing physical activity on them may result in future resentment to physical activity. Teacher enthusiasm also appears to play a critical role in maintaining activity. Goh et al.
(2014) found teachers with high levels of enthusiasm for daily 10-minute physical activity breaks in the classroom produced up to 1,000 extra steps daily during school. Conversely, the researchers noted when teacher enthusiasm waned, students daily step count during school decreased by 152 steps below baseline measurements, effectively negating the intended benefit. Therefore, timing of active programming may also contribute to success. Skouteris et al. (2014) suggested the health-centered active classroom would be most beneficial when delivered earlier in the day when students are more alert and at a higher energy point in their circadian rhythm.

While exercise and physical activity modalities could make positive change more attainable, higher costs, space confinements, and potential liability of additional equipment may prove to be too high a risk for an untested benefit. Ferrer and Laughlin (2017) promoted group activities using the student's own body weight as the primary resistance load, with activities focusing on full body movement for short durations. The active classroom setup created by McCrady-Spitzer, Manohar, Koepp, and Levine (2015) incorporated overhead ladders, balance beams, gym mats, etc., but even with a relatively low cost $(\sim 500)$, the average space needed to accommodate such structures is recommended to be at least 800 square feet, with all desks and chairs removed. Such a setup would be great for large areas, and well-funded schools, but would be challenging to implement in a standard size classroom. Additional training for teachers and students would be necessary to obtain the full benefit of such equipment, and educators would be best served to use common classroom supplies, or have the students use their own body weight for active classroom activities.

Orji, Vassileva, and Mandryk (2013) indicated restaurant goers were heavily influenced by the sight and smell of food around them, and ended up making choices based on immediate sensory feedback. Presenting students with healthy foods during class time outside of their normal lunch periods could provide a similar effect. If students are exposed to healthy foods appealing to their senses, it could promote a positive feedback loop to more healthy eating habits. 


\section{CONCLUSIONS}

There exists an abundance of evidence supporting the use of active classrooms from early childhood development through adult education. Little research has been devoted to evaluating the health benefits of an active classroom independent of academic progress. After a comprehensive review of the literature, an active classroom appears to have the most health benefits for students when teachers obtain proper training in physical activity and nutrition, remain enthusiastic about the active classroom programming, promote inclusion and student enjoyment, and have the active classroom last at least 10 minutes daily for best results. 


\section{REFERENCES}

Abi Nader, P., Hilberg, E., Schuna, J. M., John, D. H., \& Gunter, K. B. (2018). Teacher-level factors, classroom physical activity opportunities, and children's physical activity levels. Journal of Physical Activity \& Health, 15(9), 637-643. doi. org/10.1123/jpah.2017-0218

Allison, K. R., Philipneri, A. N., Vu-Nguyen, K., Manson, H. E., Dwyer, J. J. M., Hobin, E., ... Li, Y. (2018). School and classroom effects of daily physical activity (DPA) policy implementation fidelity in Ontario classrooms: A multi-level analysis. BMC Public Health, 18(1), 1-12. doi.org/10.1186/ s12889-018-5720-2

Behrens, T. K., Holeva, W. M., Carpenter, D., Tucker, E., Luna, C., Donovan, J., . . Kelly, C. (2017). Intensity of commonlyreported classroom-based physical activity opportunities in public schools. Preventive Medicine Reports, 6(C), 157-161. doi.org/10.1016/j.pmedr.2017.02.025

Bishop, F. M. (2018). Self-guided change: The most common form of long-term, maintained health behavior change. Health Psychology Open, 5, 1-14. doi. org/10.1177/2055102917751576

Bonwell, C., \& Eison, J. (1991). Active learning: Creating excitement in the classroom. Washington, DC: Eric Clearinghouse on Higher Education.

Carlson, J. A., Engelberg, J. K., Cain, K. L., Conway, T. L., Mignano, A. M., Bonilla, E. A., . . Sallis, J. F. (2015). Implementing classroom physical activity breaks: Associations with student physical activity and classroom behavior. Preventive Medicine, 81, 67-72. doi.org/10.1016/j. ypmed.2015.08.006

Chilimoniuk, Z., Borkowska, A., Chalupnik, A., Raksa, K., Sobstyl, A., \& Piecewicz-Szczesna, H. (2018). The problem of obesity and overweight among children and youth in the world. Journal of Education, Health and Sport, 8(9), 15411547. doi.org/10.5281/zenodo.1436406

Dinkle, D. M., Lee, J., \& Schaffer, C. (2016). Examining the knowledge and capacity of elementary teachers to implement classroom physical activity breaks. International Electronic Journal of Elementary Education, 9(1), 182-196.

Edwards, S. (2015). Active learning in the middle grades. Middle School Journal, 46(5), 26-32. doi.org/10.1080/00940771.20 15.11461922

Fedewa, A., Cornelius, C., \& Ahn, S. (2017). The use of bicycle workstations to increase physical activity in secondary classrooms. Health Psychology Report, 6(1), 60-74. doi. org/10.5114/hpr.2018.71211
Ferrer, M. E., \& Laughlin, D. D. (2017). Increasing college students' engagement and physical activity with classroom brain breaks. The Journal of Physical Education, Recreation \& Dance, 88(3), 53-56. doi.org/10.1080/07303084.2017.1260945

Goh, T. L., Hannon, J., Webster, C. A., Podlog, L. W., Brusseau, T., \& Newton, M. (2014). Effects of a classroom-based physical activity program on children's physical activity levels. Journal of Teaching in Physical Education, 33(4), 558-572. doi.org/10.1123/jtpe.2014-0068

Gonzalez-Sicilia, D., Briere, F. N., \& Pagani, L. S. (2019). Prospective associations between participation in leisuretime physical activity at age 6 and academic performance at age 12. Preventive Medicine, 118, 135-141. doi. org/10.1016/j.ypmed.2018.10.017

Harris, J. (2014). Physical education teacher education students' knowledge, perceptions and experiences of promoting healthy, active lifestyles in secondary schools. Physical Education \& Sport Pedagogy, 19(5), 466-480. doi.org/10.10 80/17408989.2013.769506

Have, M., Nielsen, J. H., Ernst, M. T., Gejl, A. K., Fredens, K., Grontved, A., \& Kristensen, P. L. (2018). Classroom-cased physical activity improves children's math achievement-A randomized controlled trial. PLoS ONE, 13(12), 1-14. doi. org/10.1371/journal.pone.0208787

Howerton, M. W., Bell, B. S., Dodd, K. W., Berrigan, D., Stolzenberg-Solomon, R., \& Nebeling, L. (2007). Schoolbased nutrition programs produced a moderate increase in fruit and vegetable consumption: Meta and pooling analyses from 7 studies. Journal of Nutrition Education and Behavior, 39(4), 186-196. doi.org/10.1016/j.jneb.2007.01.010

Linker, J. M., \& Woods, A. M. (2018). "Like, we don't want to be PE teachers:" Preservice classroom teachers' beliefs about physical education and willingness to incorporate physical activity. Physical Educator, 75(1), 77-98. doi.org/10.18666/ TPE-2018-V75-11-7640

Martin, R., \& Murtagh, E. M. (2015). An intervention to improve the physical activity levels of children: Design and rationale of the 'Active Classrooms' cluster randomised controlled trial. Contemporary clinical Trials, 41, 180-191. doi. org/10.1016/j.cct.2015.01.019

McCrady-Spitzer, S. K., Manohar, C. U., Koepp, G. A., \& Levine, J. A. (2015). Low-cost and scalable classroom equipment to promote physical activity and improve education. Journal of Physical Activity \& Health, 12(9), 1259-1263. doi. org/10.1123/jpah.2014-0159 
McMichan, L., Gibson, A., \& Rowe, D. A. (2018). Classroombased physical activity and sedentary behavior interventions in adolescents: A systematic review and meta-analysis. Journal of Physical Activity \& Health, 15(5), 383-393. doi.org/10.1123/jpah.2017-0087

Nilsen, W. J., Haverkos, L., Nebeling, L., \& Taylor, M. V. (2010). Maintenance of long-term behavior change. American Journal of Health Behavior, 34(6), 643-646. doi. org/10.5993/ajhb.34.6.1

Orji, R., Vassileva, J., \& Mandryk, R. L. (2013). LunchTime: A slow-casual game for long-term dietary behavior change. Personal and Ubiquitous Computing, 17(6), 1211-1221. doi. org/10.1007/s00779-012-0590-6

Phillipson, A., Riel, A., \& Leger, A. B. (2018). Between knowing and learning: New instructors' experiences in active learning classrooms. Canadian Journal for the Scholarship of Teaching and Learning, 9(1), 1-22. doi.org/10.5206/cjsotlrcacea.2018.1.4

Podnar, H., Novak, D., \& Radman, I. (2018). Effects of a 5-minute classroom-based physical activity on on-task behaviour and physical activity levels. Kinesiology, 50(2), 251-259. doi. org/10.26582/k.50.2.17

Silva, D. R., Minderico, C. S., Pinto, F., Collings, P. J., Cyrino, E. S., \& Sardinha, L. B. (2018). Impact of a classroom standing desk intervention on daily objectively measured sedentary behavior and physical activity in youth. Journal of Science and Medicine in Sport, 21(9), 919-924. doi.org/10.1016/j. jsams.2018.01.007

Singh, J. (2017). Enhancing student success in health care programs: Active learning in a hybrid format. Journal of Instructional Pedagogies, 18, 1-14. Retrieved from http:// www.aabri.com/manuscripts/162488.pdf

Skouteris, H., Edwards, S., Rutherford, L., Cutter-MacKenzie, A., Huang, T., \& O'Connor, A. (2014). Promoting healthy eating, active play and sustainability consciousness in early childhood curricula, addressing the Ben10 problem: A randomised control trial. BMC Public Health, 14(1), 17361747. doi.org/10.1186/1471-2458-14-548

US Department of Health and Human Services. (2018). Physical activity guidelines for Americans (2nd ed.). Washington, DC: US Department of Health and Human Services.

Wolfe, W. S. (2018). Choose health: Food, fun and fitness, an experiential youth curriculum that promotes healthy eating and active play. Journal of Nutrition Education and Behavior, 50(10), 1053-1055. doi.org/10.1016/j. jneb.2017.09.011
Wolfe, W. S., Scott-Pierce, M., \& Dollahite, J. (2018). Choose health: Food, fun, and fitness youth curriculum promotes positive behaviors. Journal of Nutrition Education and Behavior, 50(9), 924-930. doi.org/10.1016/j. jneb.2017.09.008 


\section{SOTL SUMMARIES}

